\title{
Local Adaptability of Buckwheat Species in Luang Prabang Region, Lao P.D.R
}

\author{
Xoxiong Briatia ${ }^{1}$, Myung Heon Lee ${ }^{2}$, Soon Kwan Hong ${ }^{3}$, In Je Sung ${ }^{3}$, Kwang Jin Chang ${ }^{4}$, \\ Byoung Jae Park ${ }^{5}$ and Cheol Ho Park ${ }^{3}$ \\ ${ }^{1}$ Souphanouvong University, Luang Prabang, Lao PDR \\ ${ }^{2}$ Hallym College, Chunchon 200-702, Korea \\ ${ }^{3}$ Kangwon National University, Chunchon 200-701, Korea \\ ${ }^{4}$ Korea National University of Agricultural \& Fisheries, Hwasung 445-893, Korea \\ ${ }^{5}$ University Farm, Kagoshima University, Kagoshima 890-0065, Japan
}

\begin{abstract}
The potential cultivation of buckwheat species in Luang Prabang region, Lao PDR where the species has not been naturally grown and not traditionally utilized was studied to introduce buckwheat as a new agricultural material, especially for food and medicine. The growth of Tartary buckwheat species was higher than common buckwheat showing 2.3 fold of plant height compared to common buckwheat. Number of flower per plant in Tartary buckwheat (731) was three fold higher than common buckwheat (244). Dry weight per plant was respectively $1.7 \mathrm{~g}$ in Suwon No. 1, $2.6 \mathrm{~g}$ in Suwon No. 2 , and 1.4 $\mathrm{g}$ in KW45. The rate average of seed setting was similar between common buckwheat (41 to $46 \%$ ) and Tartary buckwheat (44\%). Total seed yield of Tartary buckwheat (184 kg/10 a) in 10 a could be estimated to be higher than that of common buckwheat (108 kg/10 a).
\end{abstract}

Key words - Adaptability, Seed setting rate, Seed yield

\section{Introduction}

Upland areas accounts for $80 \%$ of the Lao P.D.R. are often characterized by rugged and dissected terrain, with steep slopes and narrow valleys providing very heterogeneous conditions for agriculture. The depth, color, and chemical and physical properties of soils are all variable according to site. From north to south, east to west and from lowlands to highlands, Laos shows a variety of climatic conditions, ranging from monsoonal tropical to sub-tropical. While annual rainfall is only $1,000 \mathrm{~mm}$ in some regions, such as southern Xayabury, it can reach 3,000 $\mathrm{mm}$ in others, such as the Bolaven Plateau. Elevation also varies greatly. The air of lower regions is often hot and humid while at higher elevations it is cooler and drier. Upland villages and swidden fields are located at different altitudes, ranging from about 200 to about 1,800 metres.

The major crop in Laos is rice. The Lao PDR has been self-sufficient in rice since the end of the 1990s. In 2003 the

*Corresponding author. E-mail : chpark@kangwon.ac.kr self-sufficiency rate for rice was $116 \%$, meaning there was surplus of $16 \%$. Due to problems of distribution and poor road access though, this surplus can not be transported to rice-deficient areas. Consequently, there are still ten provinces in the north and northeast that do not have enough rice (NAFRI, NAFES, NUOL, 2005).

Luang Prabang is a city located in north central Laos (19 88 N, 10213 E), on the Mekong River about 425 km north of Vientiane, and the capital of Louangphrabang Province. Luang Prabang is located 350 meters above sea. The current population of the city is about 103,000 . The city was formerly the capital of a kingdom of the same name. Until the communist takeover in 1975, it was the royal capital and seat of government of the Kingdom of Laos. The city is also notable as a UNESCO World Heritage Site (Wikipedia).

Buckwheat is grown in many countries as a crop that fits the farming system on marginal and fairly unproductive land. They are widely cultivated in the higher altitudes mountainous and lower altitudes areas. The main producers are China, Russian Federation, Ukraine and Kazakhstan. 
Common buckwheat has little tolerance to frost and thus is usually grown at low altitude than Tartary buckwheat. Tartary buckwheat has some frost tolerance and is grown at higher altitude where risk of frost damage is greater.

Buckwheat is a short-duration crop (2-3 months) and requires a moist and cool temperature climate to grow. Owing to its indeterminate flowering habit, buckwheat seeds mature over a long period. Therefore, flowers, green seeds and mature seeds are present on the plant at the same time. When moisture is limiting buckwheat is very sensitive to high temperature and hot dry winds.

Buckwheat is not a cereal, but its seeds (strictly achenes) are usually classified among the cereal grains because of similar usage. The grain is generally used as human foods and as animal or poultry feed. Recently, many people have interested in utilization of buckwheat because they known that buckwheat has much nutritional and pharmaceutical values including rutin and are capable of using as health food and medicine (Couch et al., 1946; Park et al., 2004). Tartary buckwheat has also attracted attention due to it's having compounds that are beneficial to health, even though it has a bitter component that limits its use as food. It has been used as an oriental medicine and health food in China, Nepal and India due to it's containing of a relatively higher amount of flavonoids, dietary fiber, vitamin B groups, fatty acids and protein compared to other Fagopyrum species (Campbell, 1997; Bonafaccia et al., 2003).

Common buckwheat is consumed in many countries in different food forms. Buckwheat noodles are the major buckwheat food in Japan, Korea and China. Probably pancakes with different thickness and different taste are the most common buckwheat foods in the Himalayan hills. In the high mountain area of the Himalayas, dish (tsampa) of buckwheat is often prepared, particularly for the occasion of traveling. Chapati and chapati-like pancakes are popular in India, Pakistan and Nepal. In the upper Dolpa of central Nepal, people consumed Tartary buckwheat everyday because it is the only available food for the people.

Buckwheat paste is frequently served for regular meals, in particular for poor people and people in high mountainous areas for whom the only available foodstuffs are buckwheat and potatoes. The buckwheat flowers produced honey of good quality and the flowers, sprouts, and green leaves are also used as a vegetable and for extracting rutin to be used in medicine (McGregor and McKillican, 1952; Park et al., 2000, 2006).

Many people have recently pursued a desire to make food products of high quality in processing buckwheat materials for health reasons. There are not many buckwheat researchers and did not have history of buckwheat research in some countries. Since 1980, a few scientists have studied buckwheat in several aspects of cultivation, breeding, food chemistry and food processing, bioactive natural compounds, and extraction of new materials for functional food, and for pharmaceutical use. Fresh or dried buckwheat sprouts are attracting a lot of attention from pharmaceutical and food companies. Roasted sprout tea is also being commercialized (Kreft et al., 2003).

However, buckwheat species are not naturally distributed and artificially grown in Lao PDR. People do not also use them for food, medicine, and others even though they have a lot of potential to be used in Lao PDR.

This paper is described a trial to determine a potential cultivation and utilization of buckwheat species in Luang Prabang region, Lao PDR for the purpose of developing a new agricultural materials, especially for food and medicine.

\section{Materials and Methods}

Common buckwheat (Korean cv. Suwon No.1 and Suwon No.2) and Tartary buckwheat (designated as KW45) were used in this experiment which was done from November $20^{\text {th }}$, 2009 to February $25^{\text {th }}, 2010$ at University farm, Souphanouvong University, Luang Prabang, Lao PDR.

At an open greenhouse without covering, experiment plots were prepared and two seeds/hole were sown at the plant density of $10 \times 10 \mathrm{~cm}$ and $30 \mathrm{~cm}$ wide row in total area $45 \mathrm{~m}^{2}$ (each plot $1 \mathrm{~m}$ x $5 \mathrm{~m}$ ) including three replications of completed random design on December, 13, 2009. The rate of seedling emergence was investigated 7 days after seed sowing. Because of drying season, hand-carried water was artificially supplied once a day. To avoid bird's invasion, greenhouse was covered with $30 \%$ shading net at ripening stage.

Data collected as follows : plant height, leaf sizes, number 


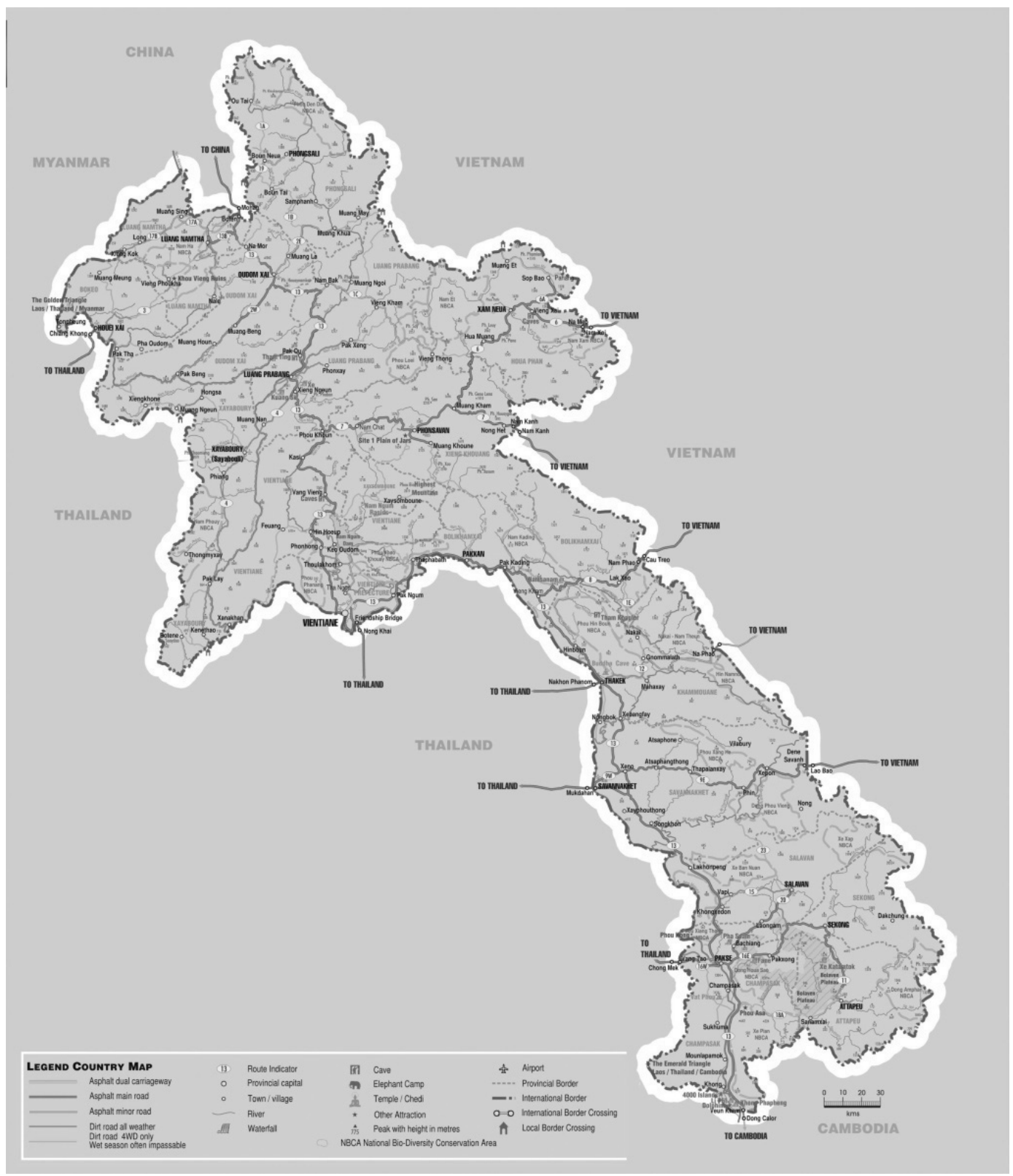

Fig. 1. Map of Lao PDR.

of branch/plant, date of flowering, date of harvesting, number of flower/plant, number of seed /plant, \% seed setting/plant, weight of 1 seed, 1,000 seeds weight, total seed weight/ treatment etc. Samples of buckwheat plants were dried at temperature $50^{\circ} \mathrm{C}$ for 48 hours.

\section{Results and Discussion}

Average of 8 years in climate in Luang Prabang region is shown in Figure 2. Average temperature of 8 years from November to February when this experiment was conducted in Luang prabang region was $21^{\circ} \mathrm{C}$ while yearly average temperature was $25^{\circ} \mathrm{C}$. Mean temperature at university farm during buckwheat growing in 2009 was $23-24^{\circ} \mathrm{C}$. Yearly rainfall for last 8 years in Luang Prabang averaged 1,195 mm. Rainfall from November to February for 8 years in Luang Prabang averaged only $75 \mathrm{~mm}$.

Seeds germinated in the soil appeared seedlings as follows 


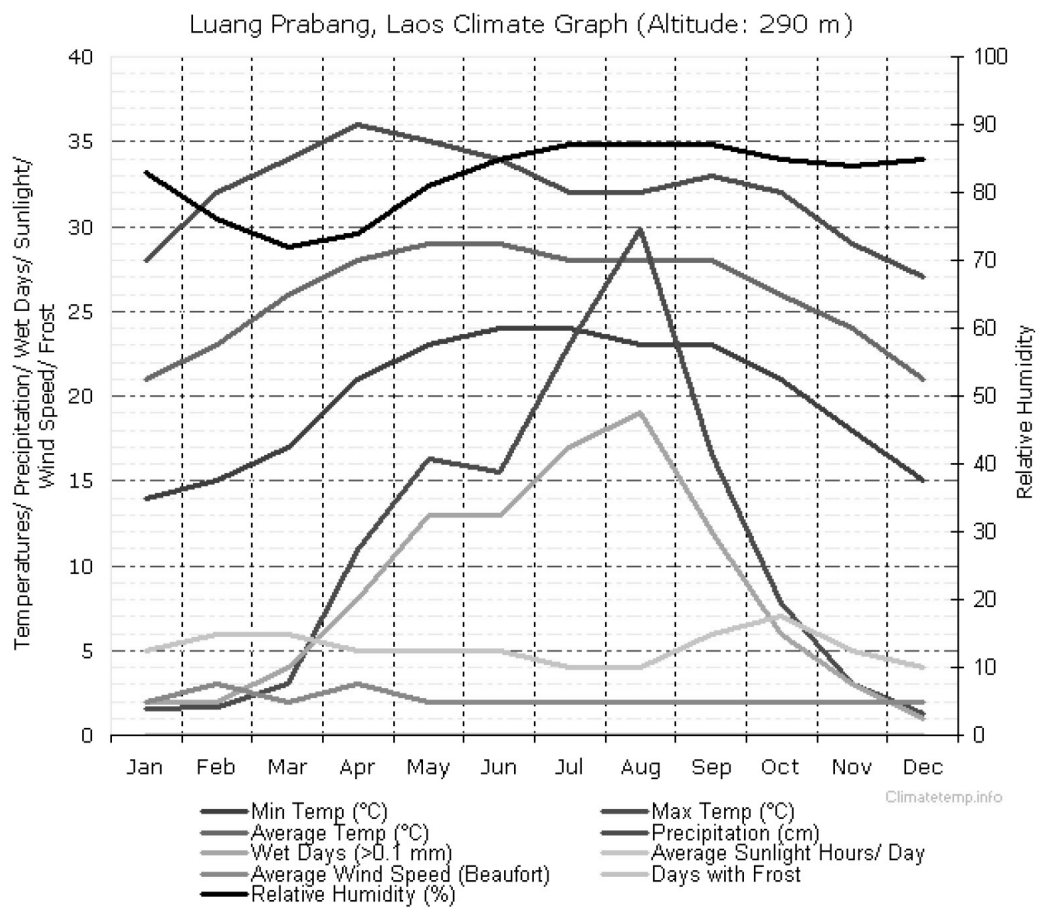

Fig. 2. Climate in Luang Prabang.

: $65 \%$ in Suwon No. $1,82 \%$ in Suwon No. 2 , and $57 \%$ in Tartary buckwheat (KW45). The relatively low seed germination was ascribed to long-term conservation of seeds in refrigerator.

All of buckwheat species grew well and showed seasonal changes in plant height, leaf length, and leaf width as shown respectively in Table 1,2, and 3. Common buckwheat species grew more quickly than Tartary buckwheat showing 2-3 fold of plant height compared to Tartary buckwheat.

At one day before harvest, Tartary buckwheat was about $10 \mathrm{~cm}$ lower than common buckwheat in plant height but was little higher than common buckwheat in number of sub branch per plant. Number of flower per plant in Tartary buckwheat was three fold higher than common buckwheat (Table 4). Dry weight per plant was respectively $1.7 \mathrm{~g}$ in Suwon No. 1, $2.6 \mathrm{~g}$ in Suwon No. 2, and $1.4 \mathrm{~g}$ in KW45.

The date of first flowering, date of $50 \%$ flowering, date of first seed mature (ripen), and date of harvest were investigated to determine how the buckwheat species respond ecologically to Luang Prabang region (Table 5). The date of first flowering and date of $50 \%$ flowering in Tartary buckwheat were 5 days later than those of common buckwheat but date of first seed
Table 1. Seasonal changes in plant height of buckwheat species after seeding

\begin{tabular}{lccc}
\hline \hline \multirow{2}{*}{ Cultivar } & \multicolumn{3}{c}{ Plant height $(\mathrm{cm})$} \\
\cline { 2 - 4 } & 12 days & 19 days & 26 days \\
\hline Suwon No.1 & 8.3 & 27.1 & 64.6 \\
Suwon No.2 & 8.3 & 27.1 & 64.4 \\
KW45 & 4.6 & 11.3 & 27.9 \\
\hline
\end{tabular}

Table 2. Seasonal change in leaf length of buckwheat species after seeding

\begin{tabular}{lccc}
\hline \hline \multirow{2}{*}{ Cultivar } & \multicolumn{3}{c}{ Leaf length $(\mathrm{cm})$} \\
\cline { 2 - 4 } & 12 days & 19 days & 26 days \\
\hline Suwon 1 & 2.5 & 5.9 & 7.5 \\
Suwon 2 & 2.2 & 5.4 & 6.9 \\
KW45 & 1.5 & 3.2 & 5.7 \\
\hline
\end{tabular}

Table 3. Seasonal change in leaf width of buckwheat species after seeding

\begin{tabular}{lccc}
\hline \hline \multirow{2}{*}{ Cultivar } & \multicolumn{3}{c}{ Leaf width $(\mathrm{cm})$} \\
\cline { 2 - 4 } & 12days & 19days & 26days \\
\hline Suwon 1 & 1.4 & 6.3 & 6.2 \\
Suwon 2 & 1.2 & 5.6 & 6.2 \\
KW45 & 0.9 & 3.3 & 5.4 \\
\hline
\end{tabular}


Table 4. Plant height and number of branch per plant at one day before harvested

\begin{tabular}{lcccc}
\hline \hline \multirow{2}{*}{ Cultivar } & \multicolumn{4}{c}{ Plant characteristics } \\
\cline { 2 - 5 } & Plant height $(\mathrm{cm})$ & No. main branch/plant & No. sub branch/plant & No. flower/plant \\
\hline Suwon 1 & 87.3 & 9.5 & 10.3 & 261 \\
Suwon 2 & 82.3 & 8.5 & 8.3 & 226 \\
KW45 & 74.9 & 7.4 & 12.7 & 731 \\
\hline
\end{tabular}

Table 5. The date of first flowering, date of 50\% flowering, date of first seed mature (ripen), and date of harvest in buckwheat species

\begin{tabular}{lcccc}
\hline \hline Cultivar & Date of first flowering (day) & Date of flowering 50\% (day) & Date of first seed mature (day) & Date of harvest (day) \\
\hline Suwon No.1 & 16 & 25 & 42 & 60 \\
Suwon No.2 & 16 & 25 & 42 & 60 \\
KW45 & 21 & 30 & 43 & 71 \\
\hline
\end{tabular}

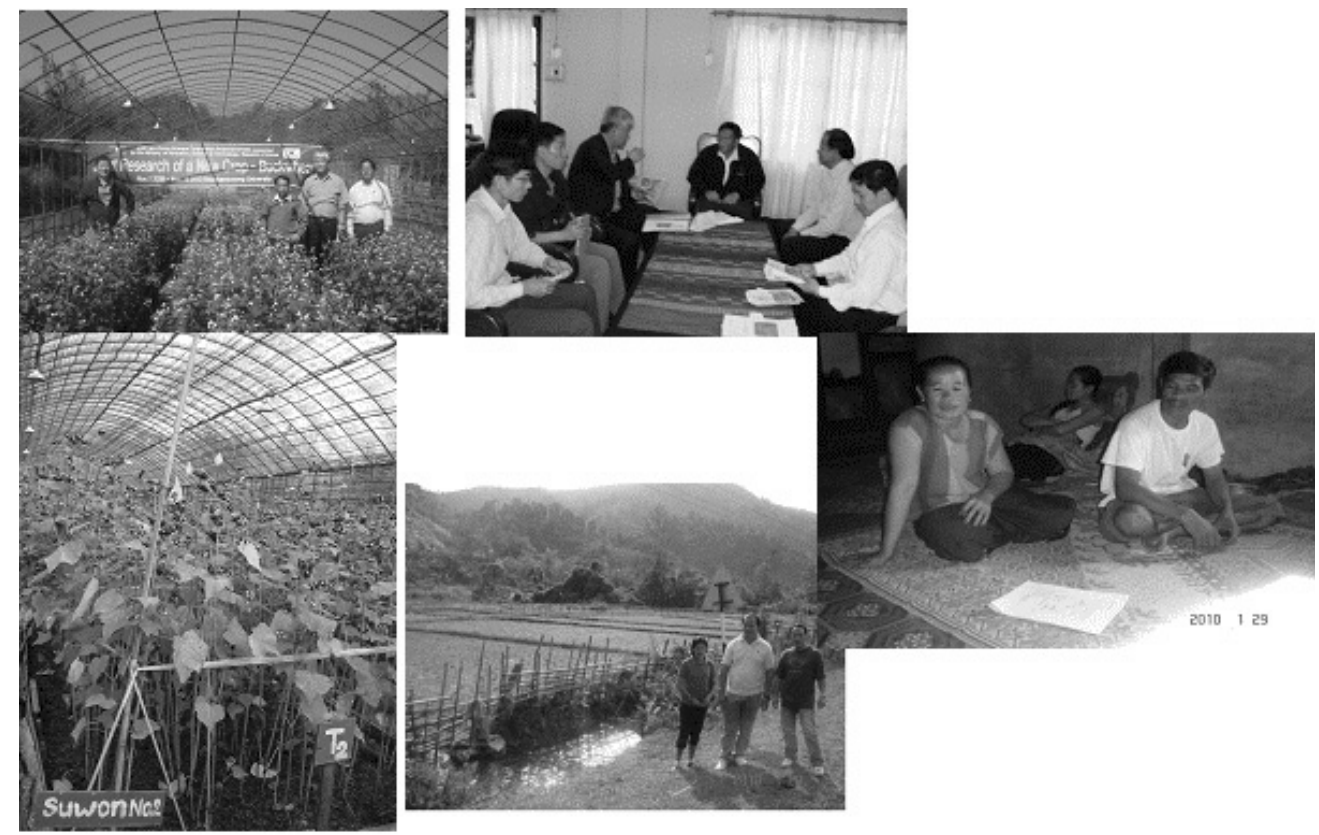

Fig. 3. Photographs of buckwheat growing in opened greenhouse at Luang Prabang and discussion among buckwheat scientists and farmers at a village in Luang Prabang region.

mature was similar to each other. There was no difference between common buckwheat cultivars, Suwon No. 1 and No. 2 but Tartary buckwheat showed 5 days later flowering and 11 days later harvesting than common buckwheat.

The rate of seed setting was similar between common buckwheat (41 to $46 \%)$ and Tartary buckwheat $\mathrm{t}(44 \%)$ as shown in Table 6. Seed weight per plant was respectively 3.5 $\mathrm{g}$ in Suwon No. 1, $3.7 \mathrm{~g}$ in Suwon No. 2, and $6.2 \mathrm{~g}$ in KW45. Because one seed weigh lower in Tartary buckwheat, 1000 seeds weight was resultantly lower than that in common buckwheat. However, total seed yield of Tartary buckwheat $(184 \mathrm{~kg} / 10 \mathrm{a})$ in 10a could be estimated to be higher than that of common buckwheat (108 kg/10 a)(Table 7).

Consequently, Luang Prabang region has much potential to grow buckwheat species even though it has higher temperature in both wet and dry season than Korea does. Lower temperature at night in Luang Prabang region even in summer may be responsible for the safe fertilization without causing any fertilizing barrier. Further studies for determining potential buckwheat growing in Lao PDR are being tried at farmer's 
Korean J. Plant Res. 25(3) : 357 362 (2012)

Table 6. Number of flower and no. of seed set per plant of buckwheat species

\begin{tabular}{lcccc}
\hline \hline \multirow{2}{*}{ Cultivar } & \multicolumn{4}{c}{ Fertility of buckwheat species } \\
\cline { 2 - 5 } & $\begin{array}{c}\text { No. flower/plant } \\
\text { (flower) }\end{array}$ & $\begin{array}{c}\text { No. seed/plant } \\
\text { (seed) }\end{array}$ & $\begin{array}{c}\text { \% seed setting } \\
\text { (full seed) }\end{array}$ & $\begin{array}{c}\text { \% seed setting } \\
\text { (non-full seed) }\end{array}$ \\
\hline Suwon 1 & 261 & 106 & 40.9 & 59.1 \\
Suwon 2 & 226 & 104 & 46.0 & 54.0 \\
KW45 & 731 & 327 & 43.6 & 56.4 \\
\hline
\end{tabular}

Table 7. Seed yield of buckwheat species in Luang Prabang

\begin{tabular}{lcccc}
\hline \hline & \multicolumn{4}{c}{ Seed yield of buckwheat species } \\
\cline { 2 - 5 } Cultivar & $\begin{array}{c}1 \text { seed weight } \\
(\mathrm{g})\end{array}$ & $\begin{array}{c}\text { Seed weight/plant } \\
(\mathrm{g})\end{array}$ & $\begin{array}{c}1000 \text { seeds weight } \\
(\mathrm{g})\end{array}$ & $\begin{array}{c}\text { Total seed yield }(\mathrm{kg}) / 10 \mathrm{a} \\
(\text { (estimated) }\end{array}$ \\
\hline Suwon 1 & 0.04 & 3.45 & 35.4 & 103.5 \\
Suwon 2 & 0.04 & 3.73 & 37.4 & 111.9 \\
KW45 & 0.03 & 6.16 & 19.7 & 184.8 \\
\hline
\end{tabular}

fields in several places (Fig. 3).

\section{Literature Cited}

Bonafaccia, G., M. Marocchini and I. Kreft. 2003. Composition and Technological Properties of the flour and bran of common and tartary buckwheat. Food Chem. 80:9-15.

Campbell. 1997. Buckwheat (Fagopyrum esculentum Moench) : Promoting the conservation and use of underutilized and neglected crops. 19. Institute of Plant Genetics and Crop Plant Research, Gatersleben/International Plant Genetic Resources Istitute, Rome, Italy.

Couch, J.F., J. Naghskiand and C.F. Krewson. 1946. Buckwheat as a source of rutin. Science 103:179-198.

Kreft, Ivan., K.J. Chang, Y.S. Choi and C.H. Park. 2003. Ethnobotany of Buckwheat. Jinsol Publishing Co., Seoul, Korea.

McGregor, W. G. and M. E. McKellican, 1952. Rutin content of varieties of buckwheat. Sci. Agr. 32:48-51.

NAFRI-National Agriculture and Forestry Research Inst., NAFES-
National Agriculture and Forestry Extension Service and NUOL-National University of Lao People's Democratic Republic, Vientiane. 2005. Improving livelihoods in the uplands of the Lao PDR. Vol. 1 : Initiatives and Approaches.

Park, B.J., J.I. Park, K.J. Chang and C.H. Park. 2004. Comparison in Rutin Content in Seed and Plant of Tartary Buckwheat (Fagopyrum tartaricum). Proceeding of the $9^{\text {th }}$ International Symposium on Buckwheat, Prague. pp. 626629.

Park, C.H., Y.B. Kim., Y.S. Choi, K.Heo, S.L Kim, K.C. Lee, K.J. Chang and H.B. Lee. 2000. Rutin content in food products processed from groats, leaves and flowers of buckwheat. Fagopyrum 17:63-66.

Park, C.H., H.S. Lee, B.J. Park, M.K. Soon and K.J Chang. 2006. Development and characterization of Tartary buckwheat sprouts. Proceeding of the International Forum on Tartary Buckwheat Industrial Economy. Taiyuan, China. pp. 116-122.

(Received 14 December 2011 ; Revised 6 June 2012 ; Accepted 25 June 2012) 